\title{
Aplicación de la buena fe y la solidaridad en la emergencia de la covid-19: una comparación entre Ecuador e Italia
}

\author{
FRANCESCA BENATTI ${ }^{1}$ \\ FELIPE IGNACIO ZURITA BURBANO2*
}

\section{RESUMEN}

Este artículo aborda la aplicación de la buena fe y el principio de la solidaridad a través de la revisión del ordenamiento jurídico italiano y ecuatoriano. En ese sentido, se examina su función en el actual contexto pandémico originado por la covid-19. Sobre todo, se destaca cómo la buena fe y la solidaridad podrían utilizarse para afrontar "comportamientos abusivos", como el aumento —irracional— de los precios de mascarillas y otros instrumentos de protección frente al virus.

Palabras clave: teoría legal, derecho de los contratos, derecho civil, responsabilidad civil, doctrina jurídica.

1 Profesora de Derecho Comparado de la Università degli Studi di Padova. Abogada por la Università degli Studi di Milano. Ph. D. por la Università degli Studi di Milano. Profesora de Derecho Comparado y Derecho Chino en la Università degli Studi di Padova. Autora de los libros: Correggere e punire dalla law of torts all' inadempimento del contratto, Le forme della proprietà. Studio di diritto comparato y Etica impresa contratto e mercato, L' esperienza dei codici etici. Asimismo, de más de setenta artículos sobre derecho comparado, derecho reales contratos y responsabilidad civil. Miembro del cuerpo docente del Doctorado en Derecho Civil e Internacional y del Trabajo de la Università degli Studi di Padova. Asimismo, miembro del Consejo Editorial de Banca, Borsa e Titoli di Credito, Casa Editrice Olejnik y Diritto degli Affari. Correo electrónico: francesca.benatti@unipd.it

2 Investigador jurídico del GIDE-PUCE. Correo electrónico: FIZURITA@puce.edu.ec

* DOI: https://doi.org/10.18601/01236458.n55.06 


\section{THE APPLICATION OF GOOD FAITH AND SOLIDARITY IN THE COVID-19 EMERGENCY: A COMPARISON BETWEEN ECUADOR AND ITALY}

\section{ABSTRACT}

This article addresses the application of good faith and the principle of solidarity through the analysis of the Italian and Ecuadorian legal system. In this perspective, its role in the current pademic context caused by covid-19 is examined. Above all, it highlights how good faith and solidarity could be used to address 'abusive behaviors', such as the irrational increase of the prices of masks and other personal protection equipment against the virus.

Keywords: legal theory, contract law, civil law, liability, legal doctrine.

\section{INTRODUCCIÓN}

La cuestión de la buena fe adquiere gran importancia por dos motivos. En primer lugar, sigue representando una línea divisoria entre el common law y los sistemas de derecho civil, a pesar del progresivo acercamiento de ambas "familias jurídicas" ${ }^{3}$. Si bien, en el common law, aunque con algunas fluctuaciones, su uso es más limitado, en el derecho civil su evolución ha determinado un uso generalizado. Parte de la doctrina subrayó cómo "la pareja supuesto de hecho/cláusula general hoy describe un binomio en el sentido de que entre los dos modelos existe, precisamente, un continuo y ya no una alternativa radical" (Nivarra, 2020, p. 102). Fue emblemática la reforma contractual francesa de 2016, al consagrar un enfoque jurisprudencial consolidado que extendió la buena fe desde la fase de ejecución del contrato hasta el principio directivo que debe orientar el trabajo del intérprete.

En segundo lugar, la emergencia provocada por la covid-19 ha suscitado dudas sobre la eficacia y adecuación de los remedios tradicionales para afrontar una situación grave e impredecible, que ha tenido graves consecuencias en las relaciones contractuales. La complejidad del momento parece agravada por el estado de interdependencia de las distintas economías debido a la globalización. Esto se encuentra no solo en la fase de emergencia, en la que muchos países han impuesto el bloqueo, sino también — más tarde — en la búsqueda por iniciar una fase de normalización. Las medidas previstas para evitar una nueva propagación del contagio, así como el miedo persistente de las personas, podrían, de hecho, retrasar el regreso al periodo anterior a la pandemia, especialmente en ausencia de certeza sobre la duración de esta situación.

3 Este artículo se desarrolla como la segunda etapa de una propuesta colaborativa entre los investigadores Francesca Benatti y Felipe Ignacio Zurita Burbano con el apoyo de la Università degli Studi di Padova y la PUCE. Se adscribe al Proyecto IV-Mejora Regulatoria (GIDE) y presenta ideas preliminares que serán publicadas a manera de libro de investigación en los próximos dos años. 
En este contexto, se ha afirmado acertadamente que la elección entre la legislación de emergencia o la atribución a la jurisprudencia de la tarea de regular el momento en función del caso es difícil:

[...] si la primera opción puede parecer la más acertada en la etapa histórica actual. Sin embargo, no se puede pasar por alto que las normas jurídicas, cuya necesidad se siente, tienen la triple característica de deber ser urgentes en cuanto a su conocimiento por parte de los operadores; ser excepcionales en cuanto al hecho cuyas consecuencias deben afrontar y ser, en consecuencia, transitorias en cuanto al tiempo de vigencia. Si bien existen razones válidas para preferir que el desarrollo del derecho civil y comercial se encomiende a la formante jurisprudencial antes que, al legislativo, no se puede evitar considerar que las tres características antes mencionadas aparecen en contraste con las formas en las que incluso la jurisprudencia más capaz puede operar. (Gambaro, 2020)

Por tanto, en la complejidad del momento, no solo se considera oportuno un retorno a la buena fe, sino también su transformación en una norma de emergencia, capaz, por su flexibilidad, de permitir una adaptación a una situación impredecible y elusiva a cualquier regulación precisa. Además, seguiría siendo coherente con su función tradicional. Como todas las cláusulas generales, tradicionalmente ha tenido la función de adecuar el derecho al caso concreto y sobre todo de permitir una apertura a la realidad actual y a problemas aún no tematizados: es decir, tienden a una modernización de un derecho positivo estático. En una situación de distancia creada por el tiempo entre el ordenamiento jurídico preestablecido y la realidad social, "la tarea del jurista [...] sigue siendo superar y conciliar este contraste en un sistema que se renueva continuamente y se hace coherente" (Ascarelli, 1952, p. 70). Con una imagen muy eficaz, se ha dicho que de esta forma el oxígeno penetra en el código, adaptándolo a la vida y al entorno (Barassi, 1964, p. 406). Esto determina "no tanto que los códigos se consideren completos, sino que se reserven la elección de modalidades integradoras para sí mismos: es más bien la autosuficiencia, es decir, el poder supremo para trazar los límites del derecho estatal y establecer relaciones con otros órdenes de normas" (Irti, 1995, p. 33). Por tanto, en una fase de emergencia como la actual, la tarea de la buena fe podría ser la de permitir la identificación de nuevas reglas o flexibilizar las tradicionales.

De hecho, en Italia, la doctrina que

[...] ha denunciado a menudo el uso, a veces sin escrúpulos, del argumento constitucional en el razonamiento del derecho civil, le pareció, en varias ocasiones, un expediente conveniente para escapar de la fatiga del concepto y transmitir, a través de un razonamiento breviloquio, soluciones que deberían haberse argumentado a través de normas positivas precisas, facilitando así el control racional. Sin embargo, en los tiempos excepcionales en que vivimos, las normas positivas (dirigidas, como están, a la destrucción del vínculo más que a su conservación) ciertamente no ayudan. Precisamente por eso, hoy en día, la buena 
fe contractual y los principios constitucionales pueden y deben ser invocados para preservar, a través de ellos, la economía de contratos ideada en tiempos normales pero alterada irremediablemente, por fuerza mayor, en tiempo de emergencia. (Benedetti-Natoli, 2020)

Esta extensión del uso de la buena fe en la emergencia parecería más sencilla en el ordenamiento jurídico italiano que en el ecuatoriano, donde los esfuerzos de su concretización jurisprudencial son aún limitados, a pesar de que a partir de la entrada en vigor de la Constitución de Montecristi se ha abierto una fase de neoconstitucionalismo. En Italia se ha establecido una dirección confirmada por el Tribunal Constitucional, que vincula la buena fe al artículo 2 de la Constitución y a un cambio de clima jurídico y cultural, cada vez más alejado de un rígido positivismo para afirmar el papel creativo que desempeña la jurisprudencia. Al respecto, se ha afirmado

[...] la conciencia adquirida de la constitucionalización del canon general de buena fe objetiva y equidad, en virtud de su sinergia con el deber obligatorio de solidaridad de conformidad con el art. 2 de la Constitución, que atribuye a esa cláusula general al mismo tiempo fuerza normativa y riqueza de contenido, incluyendo también obligaciones para la protección de la persona y las cosas de la contraparte, funcionando así la relación obligatoria para proteger también el interés del interlocutor. (Sección de Casación Civil un., $15 / 11 / 2007$, n. $\left.{ }^{\circ} 23726\right)$

Sin embargo, la doctrina ha destacado que nunca se ha ofrecido un criterio para concretar el contenido solidario de la buena fe, limitándose a enunciarlo (Grondona, 2004). La misma dificultad se encuentra también en Ecuador, donde las pocas decisiones que abordaron el tema no definieron los parámetros de concretización (Corte Nacional de Justicia Sala de lo Civil y Mercantil, n. ${ }^{\circ}$ 0228-2012, f.9; Corte Nacional de Justicia, Sala de lo Civil y Mercantil, R.0199-2014, fj.46). Este aspecto es decisivo, porque permitiría extender el concepto de solidaridad a los casos en los que sea realmente necesaria y basada en las necesidades de protección de la persona.

A partir del examen de esta situación, este trabajo incorpora la metodología del derecho comparado (privado) y tiene en cuenta el debate actual al examinar la adecuación de los remedios contractuales tradicionales como la imposibilidad sobreviniente o la emergencia, considerando sus límites. A partir de lo expuesto, se desprende la necesidad de evaluar una aplicación de la buena fe y la solidaridad que permitan su adaptación intensiva al caso concreto. Sin embargo, esto no debe significar el abandono de cualquier intento de racionalización dogmática.

Si bien la solidaridad puede enriquecer el contenido de la cláusula de buena fe y prevenir comportamientos abusivos, no puede ser empleada para justificar soluciones impredecibles, que de otro modo serían difíciles de concebir o admitir dentro de la comunidad jurídica. Esto tendría repercusiones negativas, porque no permitiría establecer un debate objetivo sobre esta temática que permanecería en un nivel de emocional y moral propia de la opinión pública y la prensa no especializada. En este sentido, este 
artículo argumenta que, para perseguir una solidaridad efectiva, parecería necesario identificar las hipótesis o criterios de aplicación y los límites para evitar soluciones que pueden parecer teóricamente correctas, pero en la práctica injustas o justificadas de modo inconsistente. En definitiva, se requeriría evitar una solidaridad indiferente y reduccionista en aras de poner atención a situaciones que realmente lo merezcan.

\section{LA EMERGENCIA Y LA IMPOSIBILIDAD DE LA PRESTACIÓN}

Se observa que, en la fase de emergencia, caracterizada en muchos países por el cierre y la interrupción de las actividades productivas, la disciplina de la imposibilidad puede ser suficiente. En Ecuador el Código Civil establece que "se denomina fuerza mayor o evento fortuito al evento imprevisto que no se puede resistir, como un naufragio, un terremoto, la detención de enemigos, actos de autoridad ejercidos por un funcionario público, etc." (CC, 2005, artículo 30). A partir de esta disposición normativa, la doctrina y la jurisprudencia se han concentrado en identificar otros casos similares.

El sistema legal italiano prevé en el art. 1218 del Código Civil que el deudor que no cumpla exactamente con la ejecución debida está obligado al pago de daños y perjuicios si no prueba que el incumplimiento o demora se debió a la imposibilidad de cumplimiento derivada de causas no imputables a él. El art. 1256 del Cóc.c. it. establece que la obligación se extingue cuando por causa no imputable al deudor, la ejecución resulta imposible. Se destacó, sin embargo, que "la imposibilidad no constituye una noción abstracta, válida para todas las relaciones de obligación, y no expresa un carácter del hecho, sino que es un juicio que se formula haciendo referencia a la ejecución deducida en obligación" (Gambino, 2015, p. 192) en referencia a lo que "las partes han dispuesto expresamente o acordado implícitamente y, cuando se requieran adiciones o especificaciones adicionales basadas en un criterio general de razonabilidad y eficiencia" (Trimarchi, 2008, p. 349), según la naturaleza y objeto del contrato.

En Ecuador y en Italia, la imposibilidad sobreviniente de la actuación per factum principis en el caso de la covid-19 parece invocarse en relación con las medidas gubernamentales con las que se interrumpió o limitó la actividad productiva. Sin embargo, dado que no regula todos los casos que efectivamente han ocurrido, la doctrina ecuatoriana está siendo testigo de un debate sobre la oportunidad de extender el uso de la buena fe para enfrentar los problemas ocasionados por la pandemia de manera flexible y efectiva y las relaciones contractuales más eficientes. Sobre todo, podría permitir el mantenimiento de algunas relaciones contractuales, evitando su disolución:

esto muestra la exigencia de adecuar las prestaciones por vía de renegociar o adaptar, y procurar la satisfacción del interés contractual de las partes antes que frustrarlo del todo y terminar la relación. De esta manera, subsiste, también aquí, el deber de restablecer el equilibrio de las prestaciones conforme al espíritu de cooperación y solidaridad. (Chamié, 2008, p.133) 
Esto debe realizarse con un refuerzo de la solidaridad a través de la buena fe que permita en determinadas circunstancias una mejor remodelación de los intereses de las partes:

[...] el solidarismo contractual cuestiona el dogma de la autonomía de la voluntad según la cual el individuo es el mejor defensor de sus intereses. Pone en duda la idea de que las partes sean las únicas que deban establecer la oportunidad del contrato, y que el hecho de que este sea negociado implique necesariamente que sea equilibrado, y que sea imposible intervenir en él en aras de la seguridad jurídica. Esta doctrina busca conciliar los imperativos clásicos de la estabilidad y la seguridad jurídica con principios como la solidaridad. (Bernal, 2007, p.17)

\section{UNA "CONCRETIZACIÓN"}

Se considera que el análisis concreto y los límites de la buena fe y la solidaridad no se pueden reconstruir de manera unitaria con respecto a Ecuador e Italia: las diferentes condiciones económicas y sociales pueden y deben de hecho determinar la oportunidad de un uso más o menos extendido, a la luz de una mayor necesidad percibida de protección de la persona. Sobre todo, conviene recordar que

la buena fe se coloca en una ambigüedad de la que pueden surgir desenlaces exactamente opuestos [...] una suerte de orgía judicial o una advertencia de los jueces que puede resultar excesiva con relación al momento histórico. Es significativo que las fuentes romanas proclamen que bona fides quae in contractibus exigitur aequitatem summam desiderat. Es equilibrio en decidir en su dimensión más intensa lo que exige la buena fe. (Castronovo, 1987, p. 29)

Como bien se ha destacado, el contrato no debe ser destruido por una solidaridad social mal aplicada e incomprendida, que antes de ser hostil al contrato es hostil al mercado e implica un modelo de desarrollo económico diferente (Grondona, 2020, pp. 318-319).

En la emergencia de la covid-19, la buena fe puede servir para llenar las lagunas en los remedios tradicionales y sobretodo la insuficiencia de la legislación de emergencia. En Italia, la normativa que intenta enfrentar la situación es fragmentada e inadecuada: solo algunos contratos como los de tiempo libre o turismo (Articolo 88 bis Decreto "Cura Italia". (L. 24 aprile 2020, n. $\left.{ }^{\circ} 27\right)$ ) están regulados directamente, en otros casos se buscan soluciones como ventajas fiscales (28 del DL n. ${ }^{\circ} 34 / 2020$ ).

En primer lugar, en este momento, la buena fe puede mitigar la rigidez del derecho positivo como ocurre mediante el uso de la figura de la inexigibilidad: si el servicio aún es posible, pero implica un sacrificio excepcional e irrazonable, la imposibilidad podría calificarse como "inexigibilidad", aplicando el principio de buena fe en la relación obligatoria y en el contrato. Consideremos una empresa que no cumple porque sus proveedores están en cuarentena y fracasa, excepto que ejecute esfuerzos 
"anormales" en la ejecución de sus actividades, es decir, demasiado costosos desde el punto de vista de la eficiencia productiva. Es evidente que no se puede tampoco obligar a una empresa a respetar las tasas de producción anteriores en un momento en que hacerlo podría poner en peligro la salud de los empleados. Del mismo modo, la buena fe puede servir de criterio para establecer que incluso un cumplimiento parcial que aporte satisfacción, aunque no total, al acreedor no puede justificar la caducidad de la relación. Por ejemplo, considere que se prometió un suministro de un bien que no se puede producir en su totalidad.

Además, el tema de la aplicación de la buena fe puede cobrar aún más relevancia en la fase posterior al bloqueo, en la que muchas de las operaciones económicas realizadas antes de la pandemia deben adaptarse a una situación completamente diferente. Esto se debe a la dificultad de viajar, a la desaceleración generalizada de las economías. Ya no se trata de verificar una posibilidad o imposibilidad de ejecución, sino de determinar cómo, sobre todo, pueden sobrevivir los contratos de duración en una situación tan diferente.

Por esto, uno de los aspectos más debatidos en la emergencia de la covid-19 parece ser la posibilidad de derivar de la cláusula de buena fe la obligación de renegociar para permitir a las partes llegar a una solución adecuada a las nuevas condiciones de emergencia. La doctrina aparece dividida: mientras que la visión clásica destaca la necesidad de utilizar los remedios tradicionales y valora la certeza del derecho (Piraino, 2020), las teorías de la solidaridad hacen énfasis en la oportunidad de llegar a una solución que sea más respetuosa con los principios de justicia y equilibrio contractual (Macario, 2020). Los principios de ELI desarrollados para la covid-19 ponen énfasis también en la necesidad de que los Estados impongan el deber de renegociar sobre la base de la buena fe, independientemente de si es requerido por contrato o por ley (art. 13.2). Y advierten que, a la luz del principio de solidaridad, los Estados deben garantizar que las consecuencias de la pandemia en los contratos no recaigan sobre una sola parte, especialmente si se trata de un consumidor o una pequeña empresa. (art. 13.3 Eli principles for the COVID-19 crisis). La tesis es aceptable, pero plantea el problema de verificar concretamente cómo dividir las consecuencias entre las partes. En algunas jurisdicciones, incluida Alemania, la legislación de emergencia protegió expresamente la posición de los inquilinos; en otras, incluida Italia, la jurisprudencia utiliza los remedios tradicionales para proteger al contratista débil. Las decisiones recientes, de hecho, están afirmando la imposibilidad de la ejecución en los alquileres comerciales para justificar el impago del alquiler.

Se requieren algunas reflexiones. Es evidente que la voluntad de las partes de renegociar y adecuar el acuerdo a una situación cambiante es óptima, garantizando, por un lado, la continuación de la relación y, por otro, permitiendo su posible remodelación que tenga en cuenta no solo la fase de emergencia, sino también la de normalización. Sin duda, este deber se podría contemplar cuando fuera necesario y sobre todo si las partes lo hubieran previsto, evaluando esta posibilidad. Sin embargo, no se puede 
determinar la obligación de llegar a un resultado, ya que los intereses de las partes pueden no ser armonizados de manera justificada o racional.

El verdadero problema surge cuando no logran encontrar una solución y, por tanto, el debate sobre la renegociación se convierte en uno sobre los poderes correctivos del juez. Aquí, pueden surgir dudas sobre la capacidad del decisor para poder adaptar relaciones complejas en las que un cambio de precio no es necesariamente suficiente, sobre el momento de estas adaptaciones, que, con frecuencia, debido a la lentitud de los procedimientos, vienen después de años, sobre la misma capacidad para aplicar una solidaridad efectiva. La doctrina también subraya las posibles repercusiones económicas y prácticas de esta tesis:

[...] una renegociación de los términos de las relaciones contractuales que se encomendaron únicamente a la concretización, en el caso único controvertido, de la cláusula general de buena fe, de hecho, acarrearía enormes costes administrativos que no podrían ser Probablemente a cargo del Estado, llamado en este momento a un esfuerzo financiero de proporciones sin precedentes. De hecho, lamentablemente no es razonable creer que siempre será posible, y probablemente ni siquiera en la mayoría de los casos, llegar, antes y fuera del juicio, a un acuerdo entre las partes de las relaciones contractuales trastornadas por la pandemia, si sólo se confiara la consecución de este acuerdo. a las directrices generales de evaluación derivadas de la cláusula de buena fe. (Scognamiglio, 2020, pp. 8-9)

A menudo, no hay partes fuertes, especialmente en situaciones de emergencia, sino personas y empresas que intentan sobrevivir en un contexto inesperado. La evaluación del intérprete de la aplicabilidad de la solidaridad debe basarse en elementos objetivos y no puede causar injusticias. Un caso podría ser lo de una multinacional que sea inquilina de una persona que necesita esa fuente de ingresos para vivir dignamente. Por tanto, podemos preguntarnos cómo se puede aplicar la solidaridad en este caso. Pero la misma dificultad se encuentra cuando en un contrato a largo plazo una parte no puede permitirse un nuevo equilibrio contractual, porque esto afectaría las relaciones contractuales con otras empresas que forman parte de la misma cadena productiva o porque implicaría el despido de muchos empleados. O, en la nueva situación económica debido a la covid-19, el contrato en sí ya no tendría ningún sentido económico y, por tanto, la renegociación no podría justificarse para una de las partes.

La oportunidad de un equilibrio y su cuidadosa concretización, sin embargo, va acompañada de la necesidad de verificar si el uso de la libertad contractual no conduce a un abuso de una parte en detrimento de la otra en estos delicados escenarios. Pensemos en el comportamiento de algunas empresas tanto en Italia como en Ecuador que, ante la urgente necesidad de mascarillas y guantes, han decidido cobrar un precio superior al razonable. Tal conducta podría constituir un abuso del derecho. La figura de origen doctrinal y hoy codificada en numerosos ordenamientos jurídicos parece difícil de definir y esquiva a criterios de aplicación: muestra el perenne y nunca resuelto contraste entre derecho y justicia. En Italia, en la aplicación de la figura, un 
momento decisivo es el caso Renault. El Tribunal de Casación argumentó a la luz de los principios constitucionales — función social de conformidad con el art. 42 de la Constitución-y de la propia calificación de los derechos subjetivos absolutos, la buena fe como

[...] un canon general al que anclar la conducta de las partes, incluso de una relación privada y la interpretación del acto jurídico de autonomía privada y, contemplando la abuso, la necesidad de una correlación entre las competencias conferidas y la finalidad para la que se confieren. En este caso, exceder los límites internos o algunos límites externos de la ley determinará su ejercicio abusivo. (Sección de Casación Civil, 18/09/2009, n. 20106)

Por tanto, incluso el ejercicio del desistimiento ad nutum previsto en el contrato puede dar lugar a una indemnización por daños y perjuicios si no es conforme a la buena fe y la equidad.

El mismo razonamiento puede aplicarse en la hipótesis de la covid-19: las empresas tenían libertad para determinar el precio de las mascarillas y guantes, pero no para aprovechar el momento de manera oportunista e irrazonable, considerando la particular fragilidad económica y social. Es necesario distinguir entre las hipótesis en las que el precio establecido permite a la empresa seguir operando, pagando a empleados y proveedores y obteniendo un beneficio justo, de aquellas en las que se explota una situación de emergencia para enriquecerse de forma irrazonable. Piense en casos en los que las máscaras que normalmente cuestan $\$ 1$ se cobran $\$ 10$ o más, sabiendo que aún deben comprarse, porque son una de las pocas herramientas de protección. En estos casos, la aplicación de la figura del abuso de derecho parece correcta. De hecho, como se afirma en una decisión reciente, un abuso se produce cuando

[...] el titular de un derecho subjetivo lo ejerce de manera irrespetuosa al principio de buena fe, provocando un sacrificio desproporcionado a la contraparte y con el fin de lograr resultados superiores a los que tiene el se ha atribuido un derecho. (Tribunal de Milán, 4.03.2020, núm. 2004)

Esta perspectiva también permite evaluar los límites con los que se puede imponer un posible deber de renegociación. Partiendo de la lógica del art. 1432 y 1467 c.c.it., si una de las partes ofrece una remodelación razonable del contrato para afrontar el momento, a la luz de las circunstancias concretas, los intereses de ambas partes y de acuerdo con el sentido económico del contrato, y la otra no acepta sin oponerse a un relevante interés o razón justificada, se le podrá exigir el pago de una compensación establecida con los criterios tomados de 1328, párrafo 1, c.c. it.o, pues está prohibido pedir cumplimiento (Chinchilla Imbett, 2020). Dado que se trata de la implementación de la cláusula de buena fe, es necesario evaluar el caso específico y la naturaleza injustificada de la denegación. Por ejemplo, el abuso podría identificarse en casos de evidente disparidad en el poder de negociación, como cuando los bancos o las 
compañías de seguros están involucrados o cuando una de las partes no ha tenido ningún malestar por la pandemia, mientras que la otra se encuentra en condiciones difíciles. En este caso, también si las partes hubieran mostrado posiciones e intereses no lejanos en una fase de renegociación y esto resulta de indicadores objetivos o el contrato proporcionara parámetros o indicaciones claras para una remodelación, también se podría permitir al juez intervenir para proteger la ratio de ser de la operación y las estructuras económicas construidas por los contratistas.

Además, un abuso puede configurarse con respecto a la conducta del deudor: conviene recordar que otro deber que se remonta al principio de buena fe es el de mitigar los posibles perjuicios que surjan a la contraparte en esta situación. De hecho, es evidente que un contratante no debe limitarse a reconocer las dificultades derivadas de las medidas por la covid-19 o del cambio de circunstancias y, en todo caso, considerar justificado un posible incumplimiento contractual, traspasando el riesgo a la contraparte. También sería un abuso en este caso. En cambio, debe tratar de evitar los perjuicios $\mathrm{y}$, en todo caso, tratar de garantizar la satisfacción del acreedor en la medida de lo posible, siempre que los esfuerzos requeridos sean razonables y no excesivamente gravosos, teniendo en cuenta la naturaleza y las características del servicio.

Se observa que el principio del abuso nació, según Atienza y Manero (2004), precisamente para responder a la deshumanización de la relación jurídica y, a pesar de la conciencia de la ilusoria idea de que basta con moralizar la ley, ha demostrado ser una herramienta útil para responder a la arbitrariedad, a la anormalidad y la ofensa al sentimiento común (Rescigno, 1965, p. 289). Sin embargo, no debe considerarse "bien fundado en sí mismo, independientemente de cómo se reconstruya y utilice. Mucho menos [...] se puede considerar un buen argumento por la estigmatización del comportamiento que opera" (Velluzzi, 2019, p. 340). Por tanto, es necesario prestar atención a la motivación y justificación de su uso, tratando de equilibrar las necesidades de certeza y justicia. No se puede utilizar únicamente para corregir negocios incorrectos o pronósticos inexactos.

Esto muestra, especialmente en lo que se refiere al Ecuador — donde la discusión aún se encuentra en estado embrionario-, la relevancia de un debate sobre la reorientación del contrato hacia los principios de solidaridad y buena fe que también nos permita enfrentar eventos que han debilitado significativamente a las pequeñas economías y a los más "frágiles agentes económicos".

\section{CONCLUSIONES}

La cuestión de la aplicación de la buena fe y la solidaridad parece hoy decisiva en una fase tanto de emergencia como de transición. Por un lado, estamos, de hecho, ante una situación impensable hasta hace poco y que hubiéramos considerado propia de una película de ciencia ficción. Por otro lado, no sabemos cómo saldremos de este momento, qué equilibrios se alterarán, sobre qué bases y perspectivas tendrá que comenzar la reconstrucción. Esto concierne no solo a las condiciones económicas, 
sociales y políticas, sino también a las legales. Será inevitable una transformación jurídica, cuya evolución no puede preverse, en la que las cláusulas generales serán centrales por su naturaleza.

Entonces es necesario insistir en la necesidad del equilibrio entre previsibilidad y seguridad jurídica y en un uso de la solidaridad que permita limitar los comportamientos abusivos, que socavan la corrección y la confianza de las relaciones contractuales. En ese sentido, únicamente una cuidadosa concretización puede permitir de facto la necesaria construcción dogmática del principio de solidaridad.

Por tanto, es importante huir de una concepción retórica y basarla en

el hombre concreto, con debilidades, límites e incapacidades que condicionan su existencia y acción; en la insistencia en reconocer su autonomía y en prevenir y eliminar cualquier actitud o tentación de convertirla en objeto o herramienta de la actividad ajena; sobre la pretensión de la unicidad e irrepetibilidad de cada individuo, más allá de cualquier recurso técnico y cualquier descubrimiento científico que facilite el cuestionamiento del misterio de la vida. (Rescigno, 2004, p. 398)

\section{REFERENCIAS}

ASCARELLi T. (1952). Studi di diritto comparato e in tema di interpretazione. Milano: Giuffrè.

Atienza M. y Manero J. R. (2004). Illeciti atipici. L'abuso del diritto, la frode alla legge, lo sviamento di potere, Il Mulino, Bologna.

BARASSI, L. (1964). La teoria generale delle obbligazioni, II, Le fonti, Giuffrè, Milano.

BenedetTi, A. M. y NATOl, R. (2020). Coronavirus, emergenza sanitaria e diritto dei contratti: spunti per un dibattito. https://www.dirittobancario.it/editoriali/alberto-maria-benedettie-roberto-natoli/coronavirus-emergenza-sanitaria-e-diritto-dei-contratti-spunti-undibattito

BERNAL-FANDiÑO, M. (2007). El solidarismo contractual-especial referencia al derecho francés. Universitas Bogotá, (114), 17. https://revistas.javeriana.edu.co/index.php/vnijuri/article/ view/14588

Castronovo, C. (1987). L'avventura delle clausole generali. Il principio di buona fede. Milano ì, Giuffrè, pp. 19-29.

Chamié, J. (2008). Equilibrio contractual y cooperación entre las partes: el deber de revisión del contrato. Revista de Derecho Privado, 14, 113-138.

Chinchilla ImbetT, C. (2020) El rol de la excepción de incumplimiento contractual en los tiempos de pandemia. Del "remedio de autotutela" que suspende el contrato a los límites en su ejercicio basados en la solidaridad contractual. Ensayos de la Revista de Derecho Privado Universidad Externado de Colombia, 183-20.

European law institute (2019). Eli principles for the COVID-19 crisis. https://www.europeanlawinstitute.eu/fileadmin/user_upload/p_eli/Publications/ELI_Principles_for_the_COVID-19_Crisis.pdf 
GAmbaro, A. (2020). Regolamentare i contratti B2B a circostanze eccezionali come Covid-19. https://www.huffingtonpost.it/entry/regolamentare-i-contratti-a-circostanze-eccezionalicome-covid-19_it_5eb152c5c5b60a92778203ec

Gambino, F. (2015). Il rapporto obbligatorio, Trattato di diritto civile diretto da Sacco, R., Torino, Utet.

GRONDONA, M. (2004). Solidarietà e contratto: la lettura costituzionale della clausola di buona fede. Rivista trimestrale di diritto e procedura civile, pp. 727-744.

Grondona, M. (2020). Dall'emergenza sanitaria all'emergenza económica. Actualidad Jurídica Iberoamericana, pp. 314-325.

IRTI, N. (1995). Codice civile e società política. Laterza, Roma-Bari.

MACARIO, F. (2020). Coesistenza e complementarità tra fattispecie tipizzata dal legislatore e uso giurisprudenziale delle clausole generali: l'esempio della proposta di riforma della disciplina in tema di sopravvenienze. Questione giustizia, pp. 87-93

NivarRA, L. (2020). Fattispecie e clausola generale: alternativa o binomio? Questione giustizia, pp. 100-103.

PIRAINO, F. (2020). La normativa emergenziale in materia di obbligazioni e contratti, I Contratti, en curso de publicacion.

Rescigno, P. (1965). L'abuso del diritto. Rivista di diritto civile, I, pp.205-290.

Rescigno, P. (2004). Laurea ad honorem conferita dalla facoltà giuridica "La Sapienza" di Roma a Sua Santità Giovanni Paolo II. Laudatio di un giurista laico., Rivista di diritto civile, I, pp. 395-399.

Scognamiglio, C. (2020). L'emergenza Covid-19: quale ruolo per il civilista? pp.1-10.

TRIMARCHI, P. (2008). Incentivi e rischio nella responsabilità contrattuale. Rivista di diritto civile, I, 341-359.

VelluzZI, V. (2019). Dietro la maschera. Abuso del diritto soggettivo e interpretazione. Ballarani, A. (ed), Novecento del diritto. Torino, Giappichelli, 315-340. 